\title{
Informatization of teaching based on interdisciplinary connections of robotics with other subjects
}

\author{
Zhadyra Yermekova ${ }^{1, *}$, Nina Stukalenko ${ }^{2}$, Elmira Kozhabekova ${ }^{3}$, Akmaral Magauova $^{4}$, \\ Pazylbek Sapargali ${ }^{3}$, and Zukhra Sadvakassova ${ }^{4}$ \\ ${ }^{1}$ Eurasian National University named after L.N. Gumilyov, St. Satpayev, 1, Nur-Sultan, Kazakhstan \\ ${ }^{2}$ National center for professional development "Orleu” Akmola region, Kokshetau, St. Abay, 71, \\ Kazakhstan \\ ${ }^{3}$ The South Kazakhstan State Pedagogical University, Shymkent, St. Baytursynova, 13, Kazakhstan \\ ${ }^{4}$ Al-Farabi Kazakh National University, Masanchi 39/47, Almaty, Kazakhstan
}

\begin{abstract}
In this work, the results of a study regarding the methodological aspects of organizing training courses in robotics in a school educational process are presented. In the course of the study, an analysis of the problem was carried out and the conditions for the effective implementation of teaching robotics to students of a comprehensive school based on developing educational technologies, integration processes and interdisciplinary communications were identified. The process of development of the cognitive interests of students in robotics was investigated in one of the specialized lyceum of the Capital city of Kazakhstan. Based on the results of the study, the theoretical foundations of the process under study are summarized, the prerequisites for updating the problem are established, and the scientific and methodological aspects of teaching robotics in the conditions of the school educational process are considered. The results obtained are of theoretical and practical importance for modern education, the implementation of the leading ideas of educational informatization.
\end{abstract}

\section{Introduction}

The robotics is one of the most important fields of scientific and technological progress in which the problems of mechanics and new technologies are in contact with the problems of artificial intelligence. This is an applied science engaged in the development of automated technical systems. Today, the mankind is in tremendously need of robots that can extinguish fires without the help of an operator, move independently on real rough terrain, perform rescue operations during natural disasters, accidents of nuclear power plants, in the fight against terrorism, and etc. In addition, with the development of robotic devices, the need arose for mobile robots designed to meet the daily needs of people (robots - nurses, nannies, housekeepers, all kinds of children's and adult toys and etc.). Specialists with knowledge in this field are already in high demand in modern production and industry.

\footnotetext{
*Corresponding author: qbabou@gmail.com
} 
There is a need to start training such specialists at school and from a very young age. Children should be able to unleash their abilities, prepare for life in a high-tech competitive world at school. According to a study by the authors [1], they concluded that robotics as a learning tool can be used in elementary, middle and high school. Therefore, robotics as an educational subject, is becoming increasingly important and relevant.

Since 2016, the Ministry of Education and Science of the Republic of Kazakhstan has developed a joint project with Nazarbayev Intellectual Schools and the "Lego Education" international company to introduce the elective course "Robotics" and to equip secondary schools with robotics rooms. A modern teacher needs to work out all the scientific and methodological aspects of introducing robotics into the educational process at school. The theoretical and methodological basis for this can be the results of pedagogical research on educational activities and the theory of teaching methods. Nevertheless, at present only in a few schools in some regions of Kazakhstan such elective courses in educational robotics are included in the educational program.

\section{Materials and methods}

When conducting the study, following types of methods were used: (1) theoretical (analysis, synthesis, classification, generalization, deduction, induction, analogy and modelling); (2) empirical (observation, survey, questionnaire and interview); (3) experimental (stating, developmental and diagnostic experiment); (4) statistical (statistical analysis of the data, qualitative and quantitative analysis of the study results).

\subsection{Justification of the relevance of the investigated problem}

The main problem of the modern educational world is the insufficient provision of engineering personnel and the low status of engineering education. Therefore, it is necessary to popularize the profession of an engineer because the use of robots in everyday life and in production requires users to have modern knowledge in the field of robot control. How to achieve this? School is the first step where we can lay the initial knowledge and skills in the field of robotics, arouse students' interest in robotics and building automated systems.

The main goal of education has become not only a simple generalization of knowledge, skills and abilities, but also personal, social and professional competence based on them, which allows one to independently receive, analyze and successfully use information, the ability to live and work rationally and effectively in a rapidly changing world [2]. In modern science, the most important and interesting discoveries are made at the intersection of sciences, and most of the sciences are complex in nature, therefore, the organization of interdisciplinary connections in teaching becomes especially important. An interdisciplinary approach as a research toolkit can provide real intrascientific reflection and methodological dialogue while maintaining the integrity of pedagogical science as an independent discipline with its own means and mechanisms of development [3].

The teacher's new role is to organize and equip an appropriate educational environment and to encourage the child to learn and act. A good example in this regard is the Lego construction, which combines specially prepared Lego sets, an elaborate task system for children and a clearly articulated educational concept. What is Lego Design? Fashion trend or demand of the times? Lego pedagogy is one of the most famous and widespread pedagogical systems at present, widely using three-dimensional models of the real world and subject-play environment for learning and developing a child. "Lego" in Danish means "smart game". The Lego constructor encourages children to work equally over their heads 
and arms. The constructor helps children to realize their ideas, build and fantasize, working with enthusiasm and seeing the result. Lego allows people to learn while playing.

\subsection{The introduction of robotics in the educational process of the school}

The introduction of elements of robotics into school subjects allows students to become interested, diversify educational activities, use active methods of group learning, and solve practical problems. Programming a real robot will help you to see the laws of mathematics not on the pages of a notebook or textbook but in the world around you. Using Lego Mindstorms NXT constructors allows you to take a fresh look at school subjects. First of all, classes are intended for general scientific preparation, the development of their thinking, logic, mathematical abilities and research skills [4].

During the 2017-2018 academic year, colleagues from Spain have introduced the methods and outcomes of training for 4 school teachers at 3 educational institutions to implement robotics in the curriculum. The key actions included: classroom assistance by a university-trained lecturer, preparation of instructional content and the evaluation of lecturer's and student's performance. The comprehension and effectiveness of the program were optimistic on the basis of the feedbacks from the survey [5].

\subsection{Implementation of intrasubject communications (ISC) of robotics with educational subjects}

The introduction of robotics into the educational process of the school allows to study natural sciences (computer science, physics, chemistry, mathematics, etc.), as well as technologies (achievements of science and technology) in the process of exciting practical exercises. This helps to intensify the introduction of robotics in teaching of various subjects [6].

Our German colleagues note that education planners recognize that robotics is an excellent platform for teaching 21st century skills [7]. Robotic problem solving develops students' innovative, creative and problem-solving skills, and since robotics spans multiple curriculum subjects, students must learn and apply their knowledge in science, engineering, mathematics, and computer programming.

The intrasubject communications through these subjects can introduce the basics of robotics into the educational process of the school and determine the role of robotics in the educational process [8].

When teaching physics, the use of robotics and Lego-technologies can take place in the following areas: demonstrations; frontal laboratory work and experiments; research project activities, and etc. Activities in these areas meet the requirements of the physics curriculum, compiled on the basis of the content of general education and the requirements for the results of basic general education presented in the state educational standard.

In the content of informatics, the conceptual apparatus is supposed to be divided into three concentrates: concepts related to the description of the information process; concepts that reveal the essence of information modeling; concepts that characterize the use of computer science in various fields, primarily: technology, management, socio-economic sphere. For a computer science teacher, in addition to the content and the number of hours allocated to the subject, information about new approaches to teaching is important, which is an activity approach.

The use of robotics in labor training is not so much a fashionable trend as a real necessity that makes a modern school competitive, and a lesson truly effective and productive for all participants in the educational process. Robotics allows us to comprehend the relationship between different fields of knowledge on the basis of reduced analogies of 
various mechanical devices modeled by the hands of the child himself. The Lego models, interesting and uncomplicated in assembly, give a clear idea of the work of mechanical structures, of force, motion and speed. The principle of learning "step by step", which is the key for Lego, provides the student with the opportunity to work at their own pace.

In addition, all school Lego kits are designed for group work and learning to work together, as a result of which students simultaneously acquire both the skills of cooperation and the ability to cope with individual tasks that are part of the overall task [9].

Lego education forms the cognitive interests of the intellectual and creative abilities of students; independence in obtaining new knowledge and practical skills; motivation of students' learning activities based on a personality-oriented approach. And, according to the author [10], it provides a variety of programs that enable students to actively learn through construction, engineering and design.

\subsection{Experimental work on the introduction of robotics in the educational process at school}

In some schools, experimental work is underway to introduce the basics of robotics into the educational process, schools acquire modern computers and Lego robots are also being purchased. Teachers master and use new equipment in the educational process, but there are a number of problems in this work. First, on the subject of "Fundamentals of Robotics", there are insufficiently developed programs and manuals. In addition, teachers must learn the programming language. They urgently need refresher courses in this area. Thirdly, the contradiction between the need to include robotics in the educational process of students in order to obtain educational results in demand on the labor market, and the underdevelopment of these issues in the scientific and methodological context, was clearly identified. Fourth, the directions and methods of teaching robotics in high school are currently not clearly defined [11].

It has been clearly indicated that more research is needed to indicate how to work with educational robotics to support students' scientific skills [12].

The requirements of the time and society to the information competence of students are constantly growing. Students must be mobile, modern, ready to develop and innovate. Often, the real state of the formation of information competence of students (in the context of using robotics) does not allow them to meet these requirements [13].

Analysis of the research problem showed that there is a lack of sources of information on the use of robotics in the educational process, a lack of didactic and methodological aids. According to the opinion of the authors of the scientific article [14], we believe that training of teachers in higher educational institutions is required for professional activities in the use of robotics and other products of innovative research in the educational process of a modern school.

First of all, it is necessary to develop programs for the introduction of robotics into the educational life of school, taking into account the age of students. It is necessary to determine the place and the role of robotics in a modern school, theoretically develop and practically test all the possibilities of introducing robotics into the educational space of a school. In accordance with this, the following tasks should be solved: develop various curriculum options in subjects related to robotics; consider possible ways of introducing robotics into the educational process of the school and choose the most optimal one; educators should learn the basics of Lego design and programming; develop elective courses in senior management in robotics and to test in the educational and extracurricular process; develop curricula and extracurricular club programs taking into account robotics; apply robotics in the summer schools and camps for children; generalize and disseminate the experience of implementation and use of robotics in the educational process. It is 
advisable to introduce the course "Fundamentals of Robotics" in the educational and extracurricular process, as well as to develop methods for embedding robotics in the course of computer science, technology, physics and other educational disciplines.

\subsection{The place of robotics in the curriculum of the school educational process}

There are certain difficulties in introducing robotics into the educational process of the school as an interdisciplinary course. The school curriculum does not have a separate robotics subject. This topic touches on several subjects: computer science (learning programming), physics (the physical principles of sensors work), technology (creating models of robots), the world around (models are created based on world objects), drawing (drawings of models), etc.

The study made it possible to give the following recommendations: to organize the study of robotics as an interdisciplinary course, to do this, consider the possibility of including robotics issues in the work programs of computer science and physics. In these subjects, it is only possible to partially implement the study of robotics. A more suitable subject is technology. This follows from the analysis of curricula

So, the most relevant topics on technology: "Educational design and implementation of educational projects", "Information technology", "Electrical engineering" and "Elements of mechanical engineering". It is also possible to use educational hours for robotics at the expense of the section "Artistic Processing of Structural Materials", since when carrying out projects it is necessary to use various materials like cardboard, metal, plastics, etc. Based on the program "Technology. Technical work", we recommend topics: "Elements of technology", "Training projects", "Machine mechanisms", "Assembly of a model of machines from designer products according to sketches and drawings", "Assembly of models of mechanical devices according to drawings", "Complex mechanisms", "Electromechanical devices", "Production of devices with an electromagnet", "Production of electrical devices with automation elements", "Assembly of electronic devices", "Creative design activity", etc.

In the course of our experiment, the most optimal way of robotics study as a section of technology class was found. Further, "Fundamentals of Robotics" can be offered as a separate academic subject. The program of this course can be conditionally divided into two large parts: "Design. Modeling" and "Programming". While engaged in designing, children learn simple mechanisms, learn how to work with their hands, they develop elementary design thinking, fantasy, and study the principles of many mechanisms. Knowing the basics of programming, students "revive" their models, which lead to greater interest in the subject. It is necessary to separately study the section of robotics programming at the level of grades 7-8, and in grades 5-6 to program robot models according to templates.

\subsection{The use of various teaching methods while learning "Fundamentals of Robotics"}

When teaching the basics of robotics at school, you can use different methods. For example, design teaching methods. Work on this technique makes it possible to develop students' individual creative abilities, to more consciously approach professional and social self-determination.

Research methods in teaching give students the opportunity to independently replenish their knowledge, to delve deeply into the problem being studied and suggest ways to solve it, which is important in shaping the worldview to determine the individual development path of each student [15]. Three techniques for implementing methodological approach 
have been introduced in the work of [16]: (1) constructive learning exercises and dialoguebased education, (2) a set of cross-method and cross-discipline discussion mediators and (3) concentrating on the complexities and advantages of undertaking "real world" research.

The use of game methods in training (role-playing, business, cognitive and other educational games) provides broadening of one's horizons, development of cognitive activity, the formation of certain skills needed in practical activities, and the development of general educational skills.

Training in cooperation (team, group work) is used as the idea of joint developmental activities of adults and children. The essence of an individual approach is to go not from a school subject, but from a child to a subject, to go from those opportunities that a child has and apply psychological and pedagogical diagnostics of a person.

Project-oriented teaching, as a system of teaching methods, involves students in the process of acquiring knowledge and skills through extensive research based on complex, real-life questions and carefully designed assignments.

Information and communication technologies help to enrich the content of education by using integrated courses, such as "Fundamentals of Robotics", with open Internet access.

It is possible to apply these teaching methods with different forms of training session organization: lesson - lecture; lesson - presentation; practical lesson (assembly of models and their programming); lesson for studying material (search for information on the Internet); project defense lesson; lesson - competition, etc. Another important point is the ability to coordinate their actions with others, in order to work in a team. In addition, determining the place of "Fundamentals of Robotics" course in the educational process of the school, we can recommend four forms of organization of educational activities for the introduction of robotics in the educational process: an extracurricular club, an elective course and a computer camp in the summer. We can offer an extracurricular club "Technical creativity and robotics" in high school, an elective course in senior level "Robotics and programming", an extracurricular club "Lego-robotics" (5-6 grade), "Physical principles of sensors" (8 grade), etc. For teachers, it is recommended to conduct a master class on the topic "Robotics and computer", organize a competition "The best program of the computer camp", "The range of computer technologies: from idea to implementation", hold scientific and practical seminars "Robotics at school", "Children and technology".

\section{Results}

During the study of the problem of introducing robotics into the educational process of schools, we studied the dynamics of students' level of cognitive interest in this subject under the influence of new educational technologies. Experimental work was carried out on the basis of a specialized lyceum №82 «Daryn» in Nur-Sultan. The experiment involved 33 students. The results obtained are in the form of the tables 1,2 .

Table 1. Indicators of the level of cognitive interest of students in the study of robotics in the experimental and control groups (data of the ascertaining experiment).

\begin{tabular}{|l|c|c|}
\hline $\begin{array}{c}\text { Levels of student } \\
\text { cognitive interest in } \\
\text { learning robotics }\end{array}$ & $\begin{array}{c}\text { Experimental } \\
\text { groups }\end{array}$ & Control groups \\
\hline low & $47.2 \%$ & $45 \%$ \\
\hline medium & $32.7 \%$ & $33.3 \%$ \\
\hline high & $20.1 \%$ & $21.7 \%$ \\
\hline
\end{tabular}




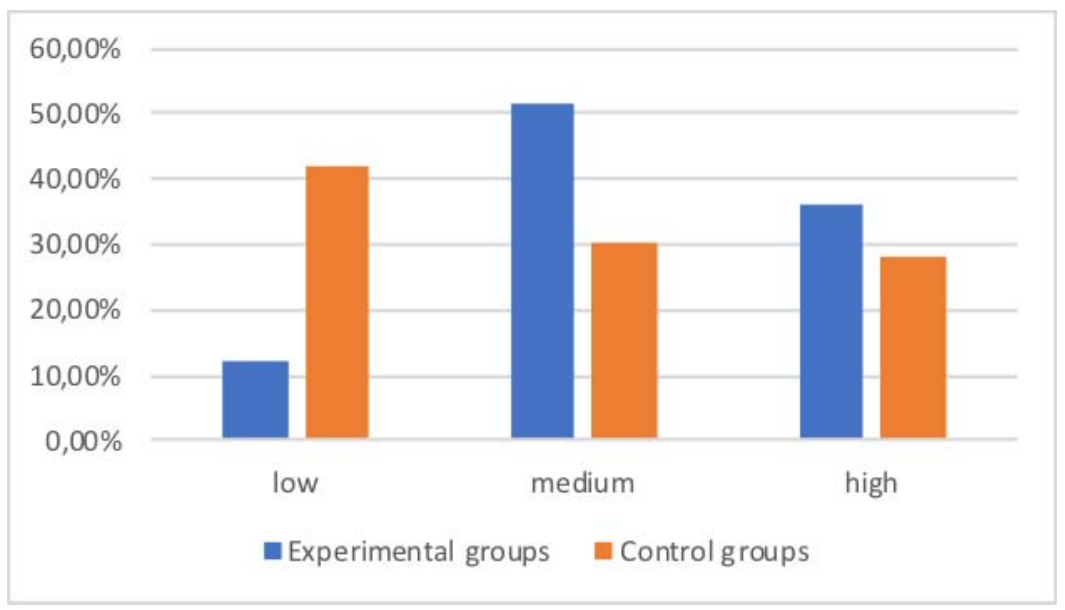

Fig. 1. Diagram of indicators of the level of cognitive interest of students in the study of robotics (data of the ascertaining experiment).

An analysis of the indicators of students' cognitive interest shows that during the experiment, the requirement of representativeness was observed in the selection of experimental and control groups for the formative stage of the experiment.

Indicators of the level of the formative experiment on the cognitive interest of students in the study of robotics in the experimental and control groups in Table 2 and Figure 2.

Table 2. Results of diagnostics of the level of cognitive interest of students in the study of robotics using new teaching technologies (data of the formative experiment).

\begin{tabular}{|l|c|c|}
\hline \multicolumn{1}{|c|}{ Level of readiness } & Experimental groups & Control groups \\
\hline low & $12.1 \%$ & $41.7 \%$ \\
\hline medium & $51.6 \%$ & $30 \%$ \\
\hline high & $36.3 \%$ & $28.3 \%$ \\
\hline
\end{tabular}

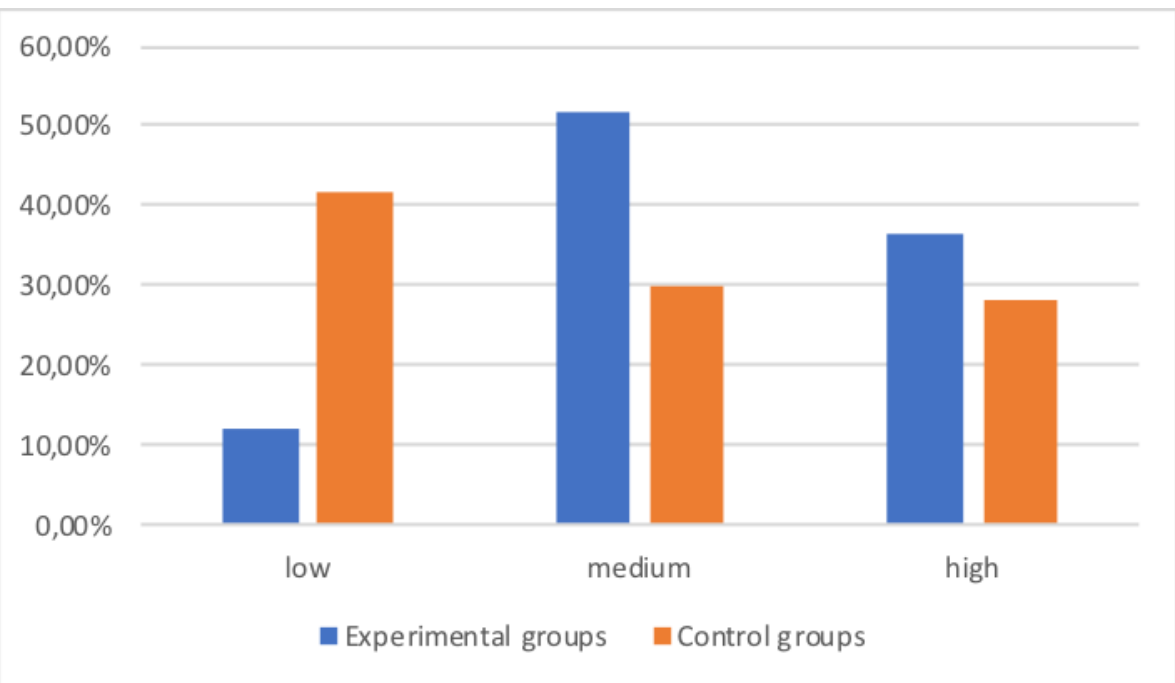

Fig. 2. Diagram of indicators of the level of students' cognitive interest in the study of robotics using new learning technologies (data from the formative experiment). 
According to the data obtained, it is clear that under the influence of new teaching technologies, the level of students' cognitive interest in the study of robotics has increased significantly. In addition, the experimental work contributed to the formation of readiness for the organization of scientific, informational and methodological support for the introduction of robotics in school education; using the capabilities of robotics as a leading means of forming students' basic ideas in the field of engineering culture; the application of technology of robotic creativity in classroom and extracurricular activities in the school system for the development of students' creative abilities in the process of designing and programming robots. Thus, the analysis of the experimental work on the introduction of robotics in the educational process of the school showed great effectiveness.

\section{Discussion}

This study was conducted on the basis of the Department of Informatics and Informatization of Education at the Kazakh National Pedagogical University named after Abai. The results of the conducted study were discussed during the department meetings, on the international scientific and practical conferences: "Using digital teaching and robotics tools in general and professional education: experience, problems, prospects" (Barnaul, 2017), "Innovations in education: guidelines and trends "(Almaty, 2017),“ Computerization of education and e-learning methodology "(Krasnoyarsk, 2018), etc. The generalized results of the conducted study are being published for the first time.

\section{Conclusion}

Analyzing the results of study on the introduction of robotics in the school educational process, we can say that this entailed: increased interest in the subject, the formation of new models of educational activity (including Lego technology), the wider use of new information and communication technologies, the development of information competencies of students and teachers, the use of project and research teaching methods, learning programming languages, improving the system work with children through the use of new methods of interactive learning, creating conditions that allow more efficiently realize the abilities and interests of students. The described activities contributed to the development of active communication, communicative behavior, generally accepted values of human society, the creation of positive motivation and desire for success and creativity.

In addition, the teacher must know the current state and prospects for the development of robotics at school as an integrative educational discipline, its place and role in the system of general education; approaches to the planning of educational process at the course of informatics, technology and entrepreneurship using a robotic module in its composition; the methodology of using robotics in the course of computer science; requirements for a complete set of informatics classroom and educational equipment for robotics.

Thus, the study showed that robotics at school provides students modern technologies of our century, contributes to the development of their communication skills, develops interaction skills, independence in decision making, and reveals their creative potential. But, as the author [17] says, robots are not the end point for better learning; the robot itself is not a real core problem; but rather a program. Robots are simple tools, while the course can assess learning outcomes and the importance of innovation to intelligent learning theories.

In the future, the introduction of a unified system of teaching robotics at school will be an important stage in the development of technical skills of schoolchildren. The "Fundamentals of Robotics" at school will help to inculcate the interest of students in 
technical creativity, thereby uncovering the talents of those students who can later become first-class engineers and technologists. That is why the introduction of robotics in the educational process of school is a big step towards primary engineering education, early career guidance and extensive informatization of education.

\section{References}

1. A. Benitti, F.B. Vavassori, Exploring the Educational Potential of Robotics in Schools: A Systematic Review, Computers \& Education 58, 3 978-988 (2012), https://doi.org/10.1016/j.compedu.2011.10.006

2. N. Stukalenko, S.A. Murzina, B.V. Kramarenko, Zh.K. Yermekova, G.M. Rakisheva, Implementation of competence approach in the professional education of prospective teachers in the higher education conditions, Int. Rev. of Manag. and Market. 6 (S3), 175-181 (2016) http://econjournals.com/index.php/irmm/article/view/2209

3. E.I. Snopkova, The relevance of an interdisciplinary approach in pedagogical research: scientific rationale, Integration of education 1 (2015). DOI: $\underline{10.15507 / \text { Inted.078.019.201501.111 }}$

4. M. Moundridou, A. Kalinoglou, Using LEGO Mindstorms as an Instructional Aid in Technical and Vocational Secondary Education: Experiences from an Empirical Case Study, Times of Convergence. Technologies Across Learning Contexts Lecture Notes in Computer Science, 5192, 312-321 https://link.springer.com/chapter/10.1007/978-3-540-87605-2_35

5. E. Jurado, D. Fonseca, J. Coderch, X. Canaleta, Social STEAM Learning at an Early Age with Robotic Platforms: A Case Study in Four Schools in Spain, Sensors 20, 13 3698 (2020) https://doi.org/10.3390/s20133698

6. U. Gerecke, B. Wagner, The Challenges and Benefits of Using Robots in Higher Education, Intelligent Automation \&amp; Soft Computing 13, 1, 29-43(2007) https://doi.org/10.1080/10798587.2007.10642948

7. A. Ernest, Kh. Myint, Robotics as an educational tool: Impact of Lego Mindstorms, Int. J. of inf. and educ technology 7(6) 437-442, ISSN: 2010-3689 (2017) DOI:10.18178/ijiet.2017.7.6.908 http://www.ijiet.org/show-88-1038-1.html

8. H. Altin, M. Pedaste, Learning approaches to applying robotics in science education, Journal of Baltic Science Education 12, 365-377 (2013) http://www.scientiasocialis.lt/jbse/files/pdf/vol12/365-377.Altin_JBSE_Vol.12.3.pdf

9. A. Aguchi, Educational Robotics for Promoting 21st Century Skills, Journal of Automation, Mobile Robotics \&amp; Intelligent Systems 8, 1, 5-11 (2014)

10. Sh. Disseler, M. Gabrielle, Students with Disabilities and LEGOC Education, J. of Educ. and Human Develop. 6, 3 (2017) URL: https://doi.org/10.15640/jehd.v6n3a5

11. E. Ospennikova, M. Ershov, I. Iljin, Educational Robotics as an Inovative Educational Technology, Procedia - Social and Behavioral Sciences 214, 18-26 (2015) https://doi.org/10.1016/j.sbspro.2015.11.588

12. I. Gorakhnath, J. Padmanabhan, Educational Robotics in Teaching Learning Process. 07 (02), ISSN 2249-9598 (2017) http://www.oiirj.org/oiirj/sept2017-specialissue $(02) / 16 . p d f$

13. Full details of the project "FIRST" and its programs (in English) www.usfirst.org/ https://www.firstinspires.org/ 
14. A.S. Magauova, M. Zhanguzhinova, Zh. Yermekova, Society. Integration. Education. Proceedins of the International Scinific Conference. Volume 1. May 27th 28 th 2016. Rezehne: Rezeknes Academy of Technologies, p.564. (2016) DOI:10.17770/sie2016vol1.1500

15. N.M. Stukalenko, B.B. Zhakhina, A.K. Kukubaeva, N.K. Smagulova, G.K. Kazhibaeva, Studying innovation technologies in modern education, International journal of environmental and science education 11, 15, 7297-7308 (2016)

16. C.A. Pfeffer, Ch.L. Rogalin, Three Strategies for Teaching Research Methods, Teaching Sociology 40, 4, 368-376 (2012) https://doi.org/10.1177/0092055x12446783

17. D. Alimisis, Educational robotics: Open questions and new challenges, Themes in Science \& Technology Education 6(1), 63-71 (2013) URL: http://earthlab.uoi.gr/thest https://files.eric.ed.gov/fulltext/EJ1130924.pdf 